\title{
Synthesis and Characteristics of Acrylol Borate as New Acrylic Gelator for Lithium Secondary Battery
}

\author{
Hyunmin Shin, Congtranh Nguyen, Byeongyeol Kim, Myonghee Han, Ju Sung Kim, and Jinhwan Kim* \\ Department of Polymer Science and Engineering, Polymer Technology Institute, Sungkyunkwan University, \\ Suwon, Gyeonggi 440-746, Korea
}

Received August 27, 2007; Revised January 8, 2008

\begin{abstract}
A novel acrylol borate was designed and synthesized by reacting acrylate monomer and boric acid. The obtained acrylol borate was used as both gelator and anion receptor for the liquid electrolyte in a lithium secondary battery. It was found that the ionic conductivity of the gel polymer electrolyte (GPE) was as high as that of the liquid electrolyte, and the thermal stability of GPE was increased when only $2 \mathrm{wt} \%$ acrylol borate was incorporated into the liquid electrolyte. These results suggest that acrylol borate can be used as an effective additive to enhance the thermal stability of the electrolyte without adversely affecting its conductivity. It is believed that the strong complex formation between boron in the gelator and the anion of the salt is responsible for the enhanced thermal stability of the electrolyte solution and the increased ionic conductivity.
\end{abstract}

Keywords: Li battery, gel polymer electrolyte, thermal stability enhancement, anion receptor, boron containing acrylate.

\section{Introduction}

Nowadays, lithium batteries are widely used for small and portable electronic devices such as laptop computers and portable media players and expanding their usages to high power applications such as HEVs. ${ }^{1-6}$ As demands for high power density batteries increase, industries face three major problems to overcome; cycle efficiency improvement, overcharging protection, and thermal stability enhancement. ${ }^{7-15}$ One of the easiest methods to solve these problems is to incorporate small amount of functional additives into the electrolyte solution while maintaining basic formulation of the electrolyte unaltered. Various additives have been investigated in an attempt to improve cycle efficiency. ${ }^{7-9}$ Among them, vinylene carbonate (VC) was found to be reliably effective for this purpose. ${ }^{10-12}$ Many additives to protect overcharging problem have been studied and polysulfone (PS) is now widely accepted as an effective one. ${ }^{13}$

So far, there is no distinct solution to overcome the thermal stability problem through adopting additive approach. The most widely used electrolyte composition is a solution of lithium hexafluoro phosphate $\left(\mathrm{LiPF}_{6}\right)$ dissolved in the mixture of organic carbonate solvents. ${ }^{16}$ For lithium ion batteries to operate properly, $\mathrm{LiPF}_{6}$ should be ionized and remain unchanged. However, as the temperature goes up ( $>$ $60{ }^{\circ} \mathrm{C}$ ), further decomposition of $\mathrm{PF}_{6}^{-}$takes place, which

*Corresponding Author. E-mail: jhkim@skku.edu consequently deteriorates the battery performance. ${ }^{17}$ If there exists in the electrolyte solution any powerful anion receptor that can interact strongly with $\mathrm{PF}_{6}^{-}$, decomposition of $\mathrm{PF}_{6}{ }^{-}$shown in Eq. (2) would be prevented and the electrolyte becomes more thermally stable.

$$
\begin{aligned}
& \mathrm{LiPF}_{6} \stackrel{\Delta}{\leftrightarrow} \mathrm{Li}^{+}+\mathrm{PF}_{6}^{-} \\
& \mathrm{Li}^{+}+\mathrm{PF}_{6}^{-} \rightarrow \mathrm{LiF}(\mathrm{s})+\mathrm{PF}_{5}(\mathrm{~g})
\end{aligned}
$$

Mc Breen et al. reported that anion receptor based on boron element can be a good candidate on this context. They concluded that ion conductivity of the electrolyte increases with addition of boron containing anion acceptor and reported that the thermal stability of lithium ion batteries (LIB) is greatly enhanced by addition of, for example, Tris-pentafluorophenyl borane (TPFPB). ${ }^{18-21}$ Recently, Lee et al. also reported that another type of boron-based anion receptor increases the thermal stability of LIB. ${ }^{22}$

On the other hand, enormous efforts have been attempted to replace liquid electrolyte by inherently thermally stable non-volatile solid electrolyte, which is called solid polymer battery (SPE). However, such an attempt failed to achieve commercially meaningful success because the conductivity of electrolyte is far below $10^{-3} \mathrm{~S} / \mathrm{cm}$, which is the value obtainable with ease for liquid electrolyte. Practically, gel polymer electrolyte (GPE) is widely accepted in industries to satisfy the compromise between liquid and solid electrolytes. There are two types of GPE; physical and chemical. 
Chemical GPE is more thermally stable and can possess greater amount of liquid electrolyte, thus giving higher conductivity. Typically, chemical GPE is comprised of liquid electrolyte with a small amount (less than $5 \mathrm{wt} \%$ ) of crosslinkable monomer which is called "gelator". Multifunctional acrylate is the most widely used in industries. ${ }^{23-25}$

In this study, we designed a new gelator which contains both boron element and acrylate unit in its structure in an attempt to combine the thermal stability enhancement effect of boron containing additive and the gelation ability of acrylate unit. We will discuss the synthesis scheme, the gel formation ability of this novel compound, and the ionic conductivity of GPE thus obtained.

\section{Experimental}

Reagents. 2-Hydroxyethyl methacrylate (HEMA), $\mathrm{CH}_{3} \mathrm{SO}_{2} \mathrm{Cl}$, boric acid, pentaerythritol triacrylate (PETA), lithium perchlorate $\left(\mathrm{LiClO}_{4}\right)$, ethylene carbonate $(\mathrm{EC})$, propylene carbonate (PC), and other solvents were purchased from Aldrich and used without further purification. Ethyl methyl carbonate (EMC) was purchased from TCI and used without fur-

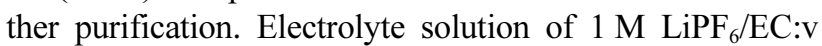
EMC $(1: 2 \mathrm{v} / \mathrm{v})$ was obtained from the Cheil Industries, Korea.

Synthesis. Boron containing tri-functional acrylate, Triacrylol borate (TAB), was synthesized through two step reaction whose scheme is given below.

Synthesis of Mesylated HEMA: In a $250 \mathrm{~mL} 3$ neck round-bottom flask filled with $\mathrm{N}_{2}$, HEMA (2.6 g, $0.02 \mathrm{~mol}$ ), triethyl amine $(4.0 \mathrm{~g}, 0.04 \mathrm{~mol})$, and methylene chloride $(100 \mathrm{~mL})$ were prepared and the flask was placed into ice bath. Methanesulfonyl chloride $(4.4 \mathrm{~g}, 0.04 \mathrm{~mol})$ was added dropwise over $1 \mathrm{~h}$ at $0{ }^{\circ} \mathrm{C}$. The mixture was stirred under $\mathrm{N}_{2}$ for $12 \mathrm{~h}$. The mixture was separated and washed with aqueous $\mathrm{HCl}$ and water. The solvent was evaporated and a clean pale brown liquid, $m$-HEMA was obtained.

Condensation Reaction between $\boldsymbol{m}$-HEMA and Boric Acid: Boric acid $(0.41 \mathrm{~g}, 0.007 \mathrm{~mol})$, sodium hydride $(0.12 \mathrm{~g}$, $0.04 \mathrm{~mol}$ ), and $0.004 \mathrm{~g}$ of hydroquinone monomethyl ether which was used as an inhibitor were added in 1,4-dioxane
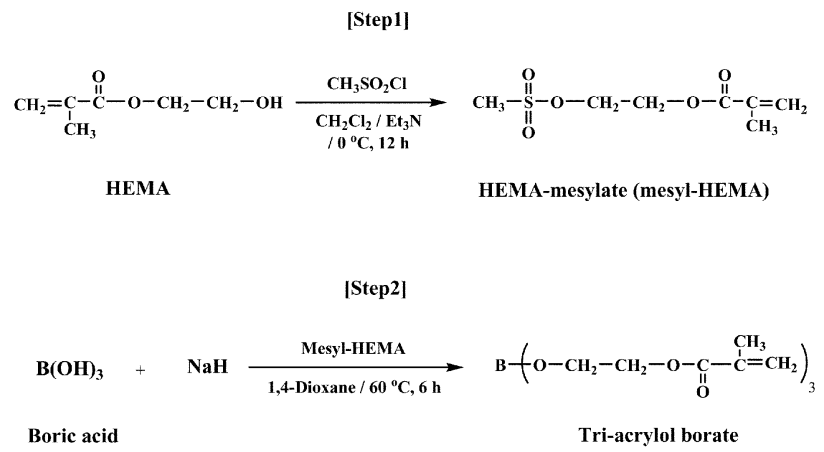

Scheme I

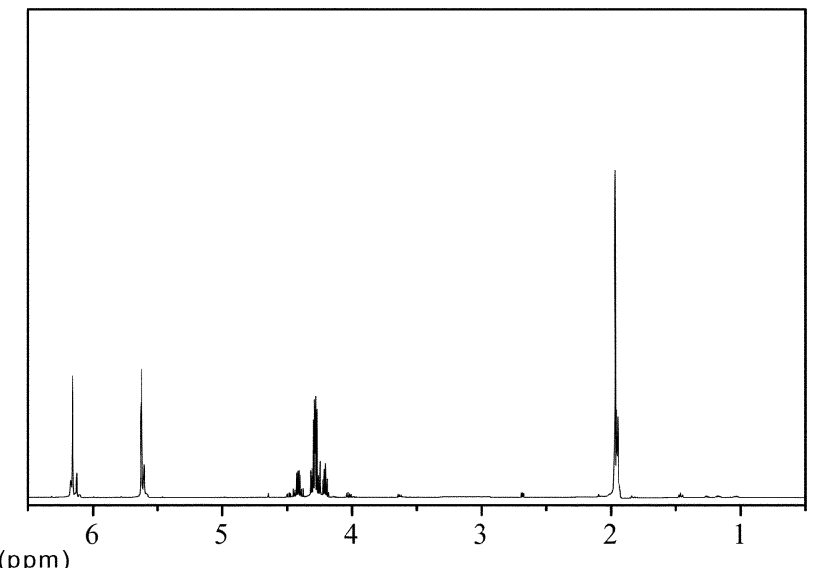

Figure 1. ${ }^{1} \mathrm{H}-\mathrm{NMR}$ spectra of tri-acrylol borate (ppm).

(150 mL). To this solution, $m$-HEMA (4.2 g, $0.021 \mathrm{~mol})$ was added dropwise over $30 \mathrm{~min}$ at $40{ }^{\circ} \mathrm{C}$. The mixture was stirred at $60{ }^{\circ} \mathrm{C}$ for $6 \mathrm{~h}$ under $\mathrm{N}_{2}$. After termination of reaction, the mixture was filtered and the product was obtained by evaporating the filtered solution. The purification was carried out by extracting the product with methylene chloride and water. The methylene chloride layer was separated and the purified tri-acrylol borate (TAB) was obtained by evaporating the solvent.

Characterization. ${ }^{1} \mathrm{H}-\mathrm{NMR}(500 \mathrm{MHz})$ spectra was obtained using a Varian Unity Inova Spectrometer in $\mathrm{CDCl}_{3}$ with TMS as an internal standard: $\delta 6.15\left[1 \mathrm{H},-\mathrm{CH}_{3} \mathrm{CCH}_{2}\right], 5.61$ $\left[1 \mathrm{H}, \mathrm{CH}_{2} \mathrm{CCH}_{3}-\right], 4.43 \sim 4.36$ [3H, -O- $\left.\mathrm{CH}_{2} \underline{\mathrm{CH}}_{2}-\mathrm{OCO}\right], 4.31$ $\sim 4.14$ [3H, -O- $\underline{\mathrm{H}}_{2} \mathrm{CH}_{2}$-OCO-], 1.93 [1 $\mathrm{H},-\mathrm{CH}_{3} \mathrm{CCH}_{2}$ ] (see Figure 1). ${ }^{26}$ The thermal properties of TAB including electrolyte solution was measured using a thermal gravity analyzer (TGA2050, TA) with a heating rate of $10^{\circ} \mathrm{C} / \mathrm{min}$ under $\mathrm{N}_{2}$ condition.

The ionic conductivity was measured using a complex impedance analyzer (Solartron 1296) over a frequency range of $100 \mathrm{mHz}-1,000 \mathrm{kHz}$. All samples in the range of 200 $\mu \mathrm{m}$ thickness were sandwiched between two stainless steel electrodes of $18 \mathrm{~mm}$ diameter and an AC perturbation of $10 \mathrm{mV}$ was applied to the cell (see Figure 2).

\section{Results and Discussion}

Gel Formation Ability. Usually, acrylate gelator is crosslinked either by light source or thermally. In this study, a thermal treat was employed to cure the electrolyte solution

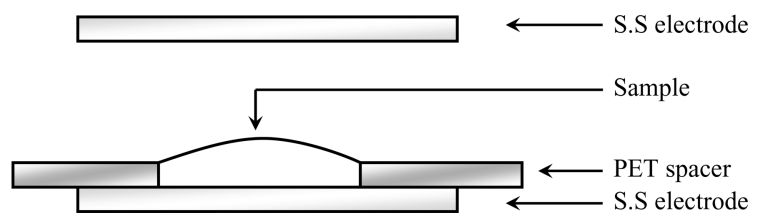

Figure 2. Preparation of the cell for measuring the ion conductivity. 


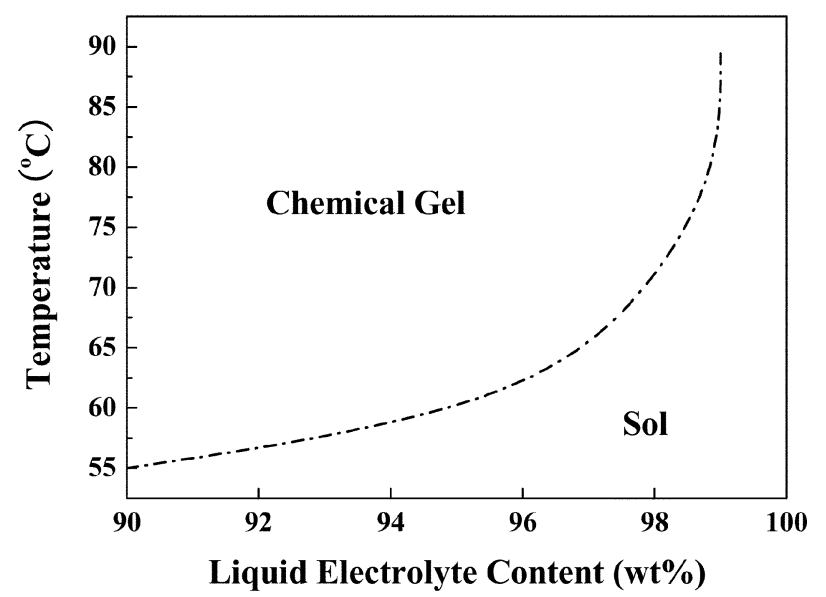

Figure 3. Gelation window for the mixtures of $1 \mathrm{M} \mathrm{LiClO}_{4} / \mathrm{PC}$ liquid electrolyte and the $\mathrm{TAB}$, gelator synthesized in this study.

which is the mixture of $\mathrm{LiClO}_{4} / \mathrm{PC}$ liquid electrolyte and gelator synthesized in this study. For this purpose, benzoyl peroxide ( $1 \mathrm{wt} \%$ on the basis of gelator amount) was added as a thermal initiator. Gel formation test was conducted for the mixtures of $1 \mathrm{M} \mathrm{LiClO}_{4} / \mathrm{PC}$ liquid electrolyte and differing amounts of gelator and the results are shown in Figure 3. As the content of gelator increases, chemical gel formation is possible at lower temperature. In another words, the gelation occurs at higher temperature as the amount of liquid electrolyte increases. Especially, it is noted that chemical gel formation is possible when the electrolyte solution contains very small amount of gelator. For example, 98/2 (wt/ wt) liquid electrolyte/gelator mixture turns into gel when cured at $70^{\circ} \mathrm{C}$. Afterwards, we use this composition as the basis for further experiments.

Thermal Stability. Our intention to incorporate the boron element into crosslinkable acrylic unit aims to enhance the thermal stability of electrolyte solution coming from anion

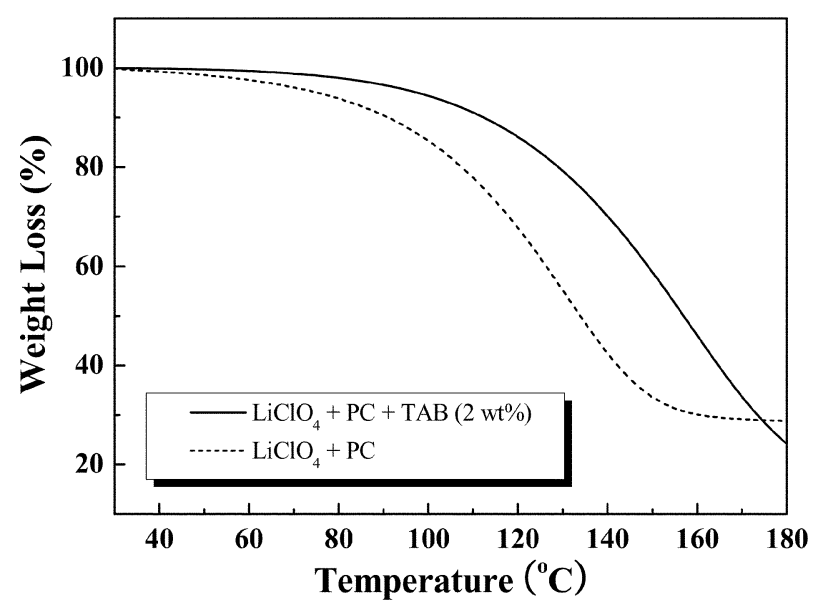

Figure 4. TGA thermograms of $1 \mathrm{M} \mathrm{LiClO}_{4} / \mathrm{PC}$ solutions with and without $2 \mathrm{wt} \% \mathrm{TAB}$.

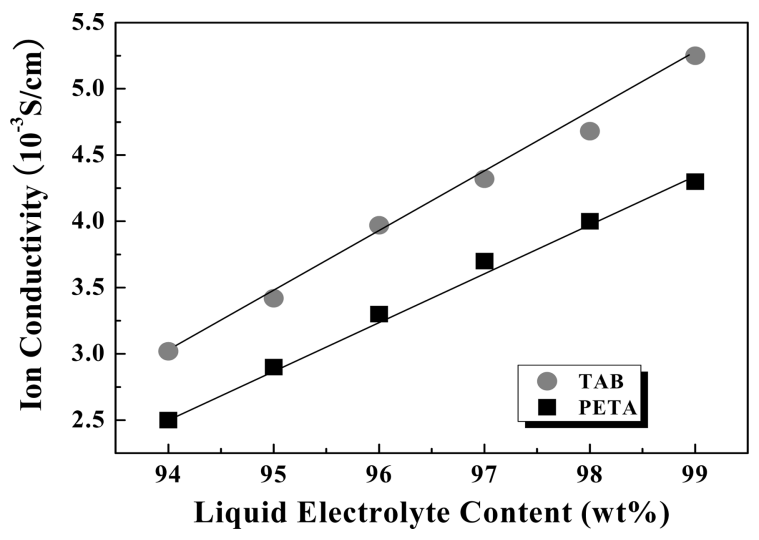

Figure 5. Ionic conductivities of the GPEs made of $1 \mathrm{M} \mathrm{LiClO}_{4} /$ PC solutions with different amounts of TAB or pentaerythritol tetraacrylate. Ion conductivities were measured at $25^{\circ} \mathrm{C}$ for the GPEs obtained after curing at $80^{\circ} \mathrm{C}$ for $1 \mathrm{~h}$.

recepting ability of the boron element. Figure 4 shows TGA thermograms of $1 \mathrm{M} \mathrm{LiClO}_{4} / \mathrm{PC}$ solutions with and without $2 \mathrm{wt} \% \mathrm{TAB}$. It is clearly seen that the addition of TAB greatly affects the thermal stability of $\mathrm{LiClO}_{4} / \mathrm{PC}$ electrolyte solution. The boron element existing in the gelator strongly interacts with anion of salt, $\mathrm{ClO}_{4}^{-}$, due to its electro-negativity nature and very stable complex is formed between them, which prevents further decomposition of anion of salt shown in Eq. (2) and consequently enhances the thermal stability of electrolyte solution. ${ }^{20,22}$ Therefore, it can be concluded that TAB containing not only boron element but also acrylic unit acts as an effective anion receptor and enhance the thermal stability of electrolyte.

Ion Conductivity. So far, we have shown that GPE can be formed with the addition of small amount of TAB into liquid electrolyte and the presence of boron element in it enhances the thermal stability of electrolyte solution. If $\mathrm{TAB}$ acts as an effective anion receptor, the ability of ion transfer, presented in the right direction of Eq. (1) would be promoted and the higher ion inductivity is expected. In Figure 5, ion conductivities of GPEs containing various amount of TAB are presented. For the comparison reasons, GPEs containing pentaerythritol tetraacrylate (PETA) which has acrylic unit only but does not possess boron element are also presented. It is clearly seen that GPE containing TAB gives higher ionconductivity than GPE containing PETA, indicating again that TAB acts as an effective anion receptor.

Electrochemical Stability. Now, the electrochemical stability of synthesized material is tested using three electrode tip cell composed of Li ribbon (counter and reference electrodes) and graphite (working electrode). For this purpose, 1 $\mathrm{M} \mathrm{LiPF}_{6} / \mathrm{EC}: \mathrm{EMC}(1: 2 \mathrm{v} / \mathrm{v})$ electrolyte solution was used as a base liquid. Figure 6 shows the cyclic voltammogram of this solution with and without $2 \mathrm{wt} \% \mathrm{TAB}$. The result clearly reveals that the electrochemical stability of electrolyte solution containing $2 \mathrm{wt} \% \mathrm{TAB}$ is far better than liquid 


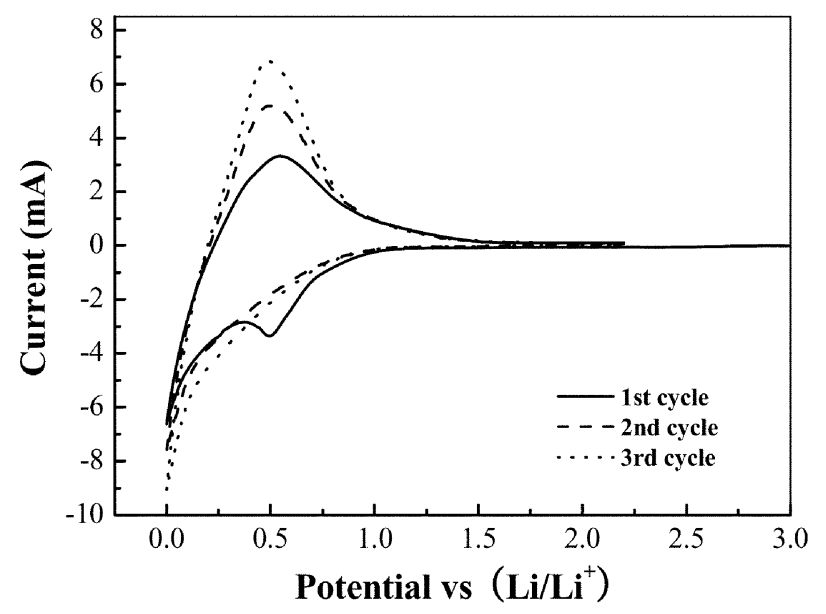

(a)

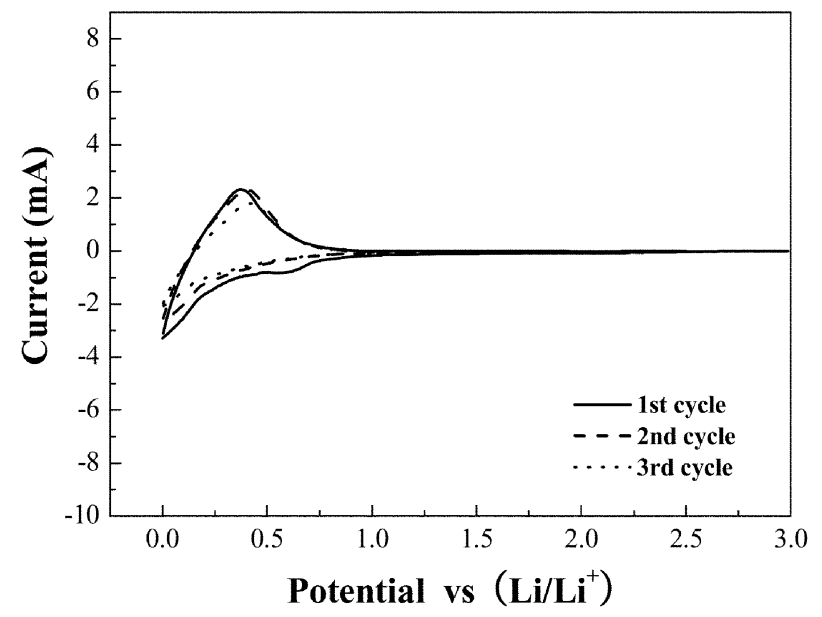

(b)

Figure 6. Cyclic voltammogram measured at $25^{\circ} \mathrm{C}$ for three electrode tip cells composed of Li ribbon (counter and reference electrodes) and graphite (working electrode) for $1 \mathrm{M} \mathrm{LiPF}_{6} / \mathrm{EC}$ : EMC(1:2 v/v) electrolyte solution: (a) without TAB and (b) with $2 \mathrm{wt} \% \mathrm{TAB}$. The cell containing $2 \mathrm{wt} \% \mathrm{TAB}$ was cured at $70{ }^{\circ} \mathrm{C}$ for $1.5 \mathrm{~h}$ before measurement.

electrolyte itself. Moreover, it is worthy to note that liquid electrolyte has reduction potential at about $0.50 \mathrm{~V}$ while electrolyte solution containing $2 \mathrm{wt} \%$ TAB shows reduction potential at about $0.7 \mathrm{~V}$ (Figure 6(a)).

\section{Conclusions}

A boron containing tri-functional acrylate, TAB, was synthesized through two reaction and employed as a gelator for GPE of Li secondary battery. It is found from gelation window experiments that chemical gel formation is possible even with the addition of $1 \mathrm{wt} \% \mathrm{TAB}$, indicating that this material can serve a good gelator. And the presence of boron element enhances the thermal stability of electrolyte solution consisting of $1 \mathrm{M} \mathrm{LiClO}_{4} / \mathrm{PC}$ and $2 \mathrm{wt} \% \mathrm{TAB}$ judg- ing from TGA thermograms, indicating that TAB can act as an effective anion receptor due to strong complex formation between Boron and $\mathrm{ClO}_{4}^{-}$. This complex formation contributes the higher ionic conductivity of electrolyte solution containing TAB when compared with that of electrolyte solution containing PETA which has acrylic units but does not possess boron element. We have also carried out actual cycle life performance test for a $\mathrm{LiCoO}_{2} / \mathrm{GPE} /$ graphite cell (600 mAh) and no significant decrease in capacity is found up to 20 cycles. Therefore, TAB synthesized in this study can be used an effective additive to enhance the thermal stability of Li secondary battery.

Acknowledgements. The authors wish to thank the Cheil Industries for providing us with the pouch cells for measuring battery performances. This work was supported by the Korea Research Foundation Grant funded by the Korean Government (MOEHRD) (KRF 2004-005-D00064 and 2006005-J04601).

\section{References}

(1) K. Tamura and T. Horiba, J. Power Sources, 81-82, 156 (1999).

(2) Y. E. Hyung, S. I. Moon, D. H. Yum, and S. K. Yun, J. Power Sources, 81-82, 842 (1999).

(3) A. N. Jansen, A. J. Kahaian, K. D. Kepler, P. A. Nelson, K. Amine, D. W. Dees, D. R. Vissers, and M. M. Thackeray, $J$. Power Sources, 81-82, 902 (1999).

(4) B. Kennedy, D. Patterson, and S. Camilleri, J. Power Sources, 90, $156(2000)$.

(5) A. G. Ritchie, J. Power Sources, 96, 1 (2001).

(6) Q. Wang, J. Sun, X. Yao, and C. Chen, J. Electrochem. Soc., 153, A329 (2006).

(7) E. Eweka, J. R. Owen, and A. Ritchie, J. Power Sources, 65, 247 (1997).

(8) R. Oesten, U. Heider, and M. Shemidt, Solid State Ionics, 148, 391 (2002).

(9) D. Aurbach, K. Gamolsky, B. Markovsky, Y. Gofer, M. Schmidt, and U. Heider, Electrochemica Acta, 47, 1423 (2002).

(10) S. Herreyre, O. Huchet, S. Barusseau, F. Perton, J. M. Bodet, and Ph. Biensan, J. Power Sources, 97-98, 576 (2001).

(11) M. Broussely, Ph. Blanchard, Ph. Biensan, J. P. Planchat, K. Nechev, and R. J. Staniewicz, J. Power Sources, 119-121, 859 (2003).

(12) M. Contestabile, M. Morselli, R. Paraventi, and R. J. Neat, $J$ Power Sources, 119-121, 943 (2003).

(13) S. Tobishima, Y. Ogino, and Y. Wantanabe, J. Appl. Electrochem., 33, 143 (2003).

(14) R. V. Morford, E. C. KellamIII , M. A. Hofmann, R. Baldwin, and H. R. Allcock, Solid State Ionics, 133, 171 (2000).

(15) X. Wang, E. Yacukawa, and S. Kasuya, J. Electrochem. Soc., 148, A1058 (2001).

(16) K. Xu, Chem. Review, 104, 4303 (2004).

(17) Lithium Ion Batteries: Fundamental and Performance, M. 
Wakihara and O. Yamamoto, Eds., Wiley-VCH, New York, 1998.

(18) H. S. Lee, X. Q. Yang, C. L. Xiang, and J. McBreen, J. Electrochem. Soc., 145, 2813 (1998).

(19) X. Sun, H. S. Lee, X. Q. Yang, and J. McBreen, Electrochem. Solid-State Lett., 5, A248 (2002).

(20) M. Herstedt, M. Stjerndahl, T. Gustafsson, and K. Edstrom, Eletrochem. Commun., 5, 467 (2003).

(21) X. Sun, H. S. Lee, X. Q. Yang, and J. McBreen, Electrochem.
Solid-State Lett., 6, A43 (2003).

(22) Y. M. Lee, J. E. Seo, N. S. Choi, and J. K. Park, Electrochim. Acta, 50, 2843 (2005).

(23) J. Y. Lee, Korea Patent 11098 (2004).

(24) J. Kim and S. J. Yoon, Korea Patent 55140 (2006).

(25) S. Okumura, S. Nishimura, N. Iwayasu, S. Yokoyama, T. Ito, T. Yabe, and K. Ichinomiya, Japan Patent 285416 (2005).

(26) J.-A. Kim, S.-Y. Choi, D.-H. Go, H.-J.Jeon, and J.-Y. Lee, Macromol. Res., 15, 337 (2007). 